\title{
Hospital Disaster Preparedness: A Model for Hospital Disaster Preparedness Based on 2014 Flood in Kelantan
}

Submitted: 01-11-2018

Accepted: 06-12-2018

Online: 26-02-2019

\author{
Norsyazana Ahmad Zamree ${ }^{1}$, Noor Azzah Said ${ }^{2}$, Suzyrman Sibly ${ }^{1}$ \\ ${ }^{1}$ Centre for Global Sustainability Studies, Universiti Sains Malaysia, \\ Pulau Pinang, MALAYSIA \\ ${ }^{2}$ Centre for Technology and Supply Chain Management Studies, \\ Faculty of Business and Management, Universiti Teknologi MARA, \\ Selangor, MALAYSIA
}

To cite this article: Ahmad Zamree N, Said NA, Sibly S. Hospital disaster preparedness: a model for hospital disaster preparedness based on 2014 flood in Kelantan. Education in Medicine Journal. 2018;10(4):69-80. https://doi.org/10.21315/eimj2018.10.4.7

To link to this article: https://doi.org/10.21315/eimj2018.10.4.7

\section{ABSTRACT}

Floods are known to be commonly occurring natural disasters in most part of the world. In 2014, the east coast of Peninsular Malaysia was affected by the worst flood ever recorded in history. The worst flood affected area were Kelantan, Terengganu and Pahang. The 2014 flood caused physical and monetary losses amounting nearly millions of dollars. Among the worst hit infrastructures in 2014 flood disaster were hospitals. This has led to the realisation of hospital disaster preparedness and management is important which needs to be closely monitored and addressed. This paper investigates the disaster preparedness level of selected hospitals affected by flood disasters in Kelantan. Guided interviews with the flood-affected hospital disaster committees were carried out and summarised in a summary table to give a clear picture of the level of hospital disaster preparedness during the 2014 flood disaster. The results show that despite the existence of disaster action plan and protocols there is no standard disaster preparedness model being used by hospitals.

\section{Keywords: Flood, Disaster, Hospital disaster preparedness, Natural disaster}

Norsyazana Ahmad Zamree, Centre for Global Sustainability Studies, Universiti Sains Malaysia, Level 5, Perpustakaan Hamzah Sendut (New Wing), 11800 USM, Pulau Pinang, Malaysia. E-mail: syazanazamree@student.usm.my

\section{INTRODUCTION}

The World Health Organization (WHO) defines natural disaster as the result of an ecological disruption or threats that exceeds the adjustment capacity of the affected community (1). The United Nations International Strategy for Disaster Reduction (2) defines disaster as a serious disruption of the functioning of a community or a society involving widespread human, material, economic or environmental losses and impacts, which exceeds the ability of the affected community or society to cope using its own resources. The impact of a disaster is different depending on its intensity and coverage area. Major natural disasters like floods, earthquakes, landslides, and droughts affect the infrastructure, agriculture, and environment. Disasters also bring about long-term emotional and mental stress to those involved in the disaster, including victims' families, the respond and rescue team as well as other civilians (3). 
The end of 2014 saw one of the worst flood disasters in the history of Malaysia (4). It has highlighted the importance of total preparedness to disasters, especially in hospitals. States that were affected by the 2014 floods were Kelantan, Terengganu, Pahang, Perak, Perlis, and Sabah, where 45,737 victims from 12,370 families were involved. The victims were placed in 284 evacuation centres around the affected states. Kelantan was the worst affected state with 26,721 evacuees from 7,633 families, placed in 115 evacuation centres (4).

Kelantan is located in the East-coast of Peninsular Malaysia exposing it to high rainfalls during the North-east monsoon season. In December 2014, Kelantan was hit by the worst flood ever where flood levels reached between 5 to 10 meters. Buildings were inundated up to the $3 \mathrm{rd}$ and 4th floor. Many people could not evacuate from their house and they took shelter in evacuation centres such as schools. Heavy rains on flood 2014 began on the 17th of December and continuously rained for three days, with heavy rainfall from $21 \mathrm{st}$ to 23rd of December 2014 in Kelantan. This was a record-setting rainfall of 1,295 $\mathrm{mm}$, equivalent to the amount of rainwater usually seen in a span of 64 days. Figure 1 shows that Kelantan River was involved in more rainfall which leads flood of the downstream area of the Kelantan Rivers in December 2014.

Consequently, the water levels of Sungai Galas, Sungai Lebir, and Sungai Kelantan which rose drastically above the danger water level. The highest recorded level of the Sungai Galas was $46.47 \mathrm{~m}$ (flood stage: $38 \mathrm{~m}$ ), the highest recorded level of Sungai

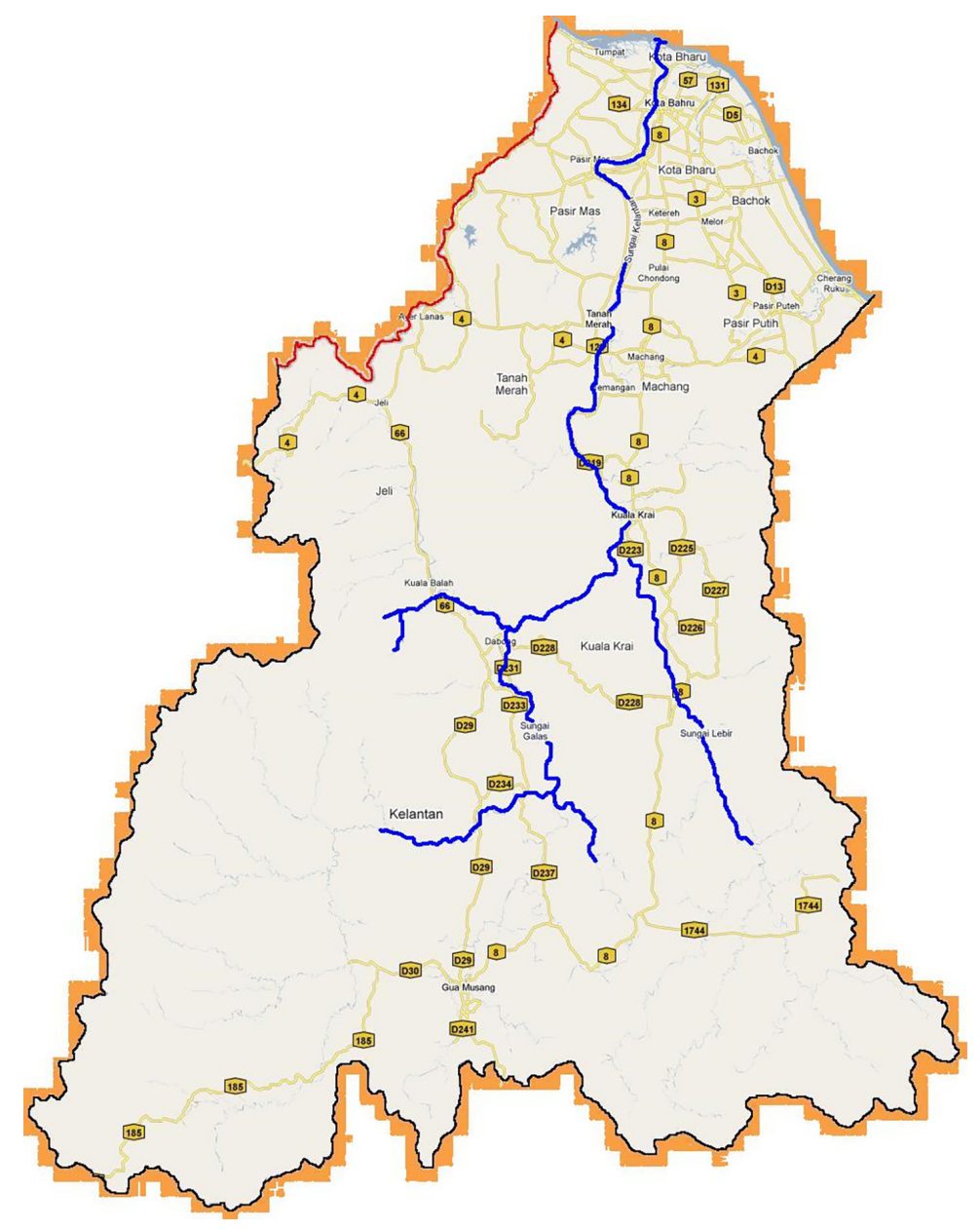

Figure 1: Map of the Kelantan Rivers (5). 
Lebir was $42.17 \mathrm{~m}$ (flood stage: $35 \mathrm{~m}$ ) and the highest recorded level of Sungai Kelantan was $34.17 \mathrm{~m}$ (flood stage: $25 \mathrm{~m}$ ). The highest level of Sungai Golok was $10.84 \mathrm{~m}$ (flood stage: $23.5 \mathrm{~m}$ ), which was over the dangerous point (5).

Datuk Mohamed Thajudeen Abdul Wahab, secretary of The National Security Council (NSC) clarified that the two main reasons for the 2014 flood which are climate change and uncontrolled land management. For example, the swelling number of trees and exploitation of land resources (6). The 2014 flood was called "yellow coloured flood" as the colour of the water is yellowish brown with the high mud contents. The route to Kelantan through East-West Highway was closed after part of the highway at the $65 \mathrm{~km}$ near to Puncak Banjaran Titiwangsa collapsed. The Gua Musang-Kuala Krai road was closed to all traffic (7). Figure 2 shows the "yellow coloured flood" in Kelantan, December 2014.
The standard of critical river levels termed by the Department of Drainage Malaysia organisation was shown in Figure 3. There are four levels namely normal level, caution level, warning level, and danger level followed by the implementation of flood forecasting and public evacuation. Caution level shows the river level exceeding the normal level and alert people to beware. The warning level alerts the public when the river level reaches to danger level and evacuation of the nearby residents prepared. Danger level is when the river level will overflow and overtops the riverbank and the evacuation of the public are executed.

December 2014 was an extreme flood event in Malaysia history. This flood caused huge financial losses where the estimated loss to hospitals and clinics amounted to RM281 million (8). The floods occurred in two phases. When the flood occurred in the first wave on 17th December 2014, it does not involve the hospital yet, but traffic towards Kota Bharu was blocked in

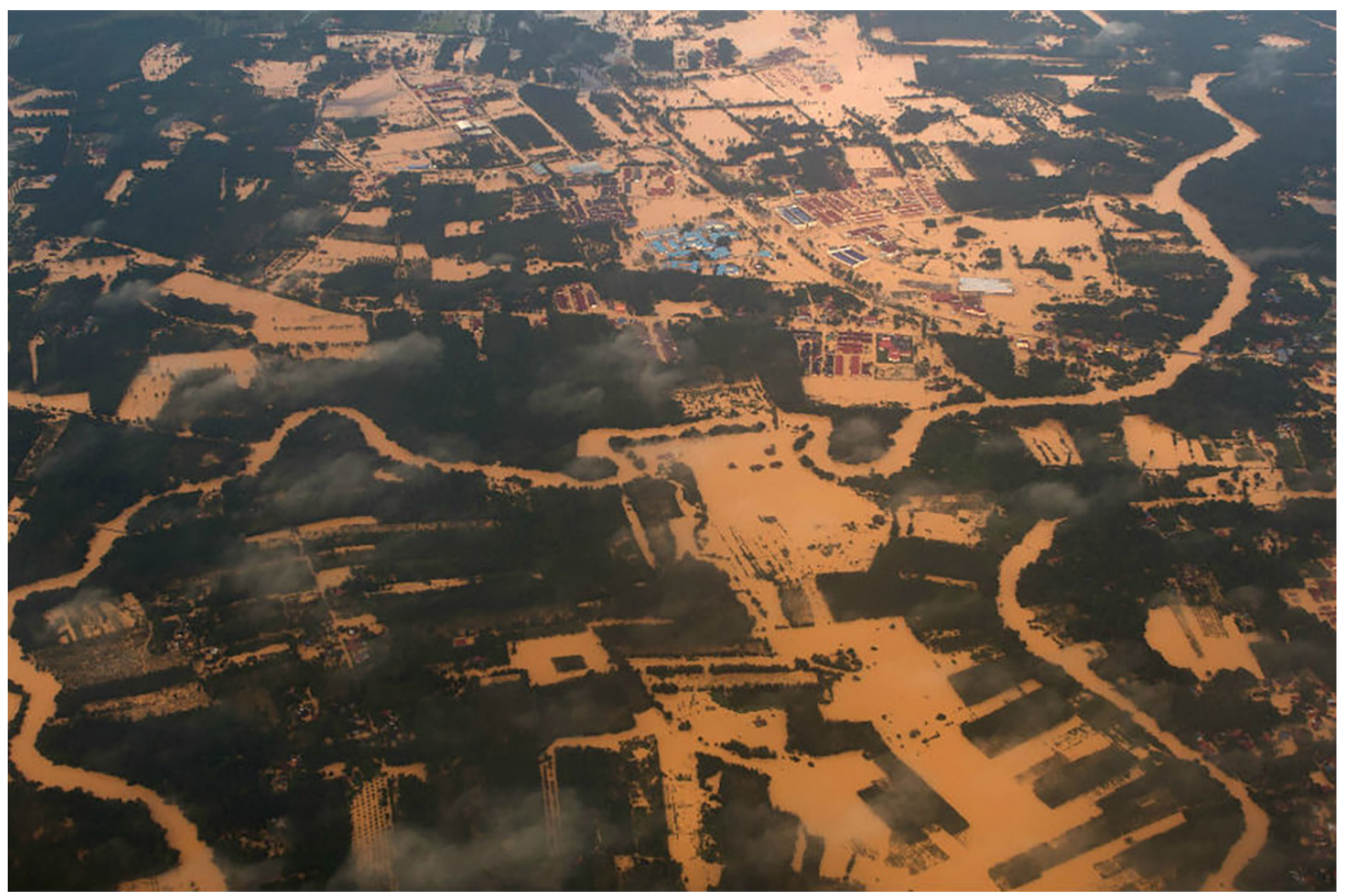

Figure 2: Area of Kelantan flood "yellow coloured flood" December 2014 (6). 


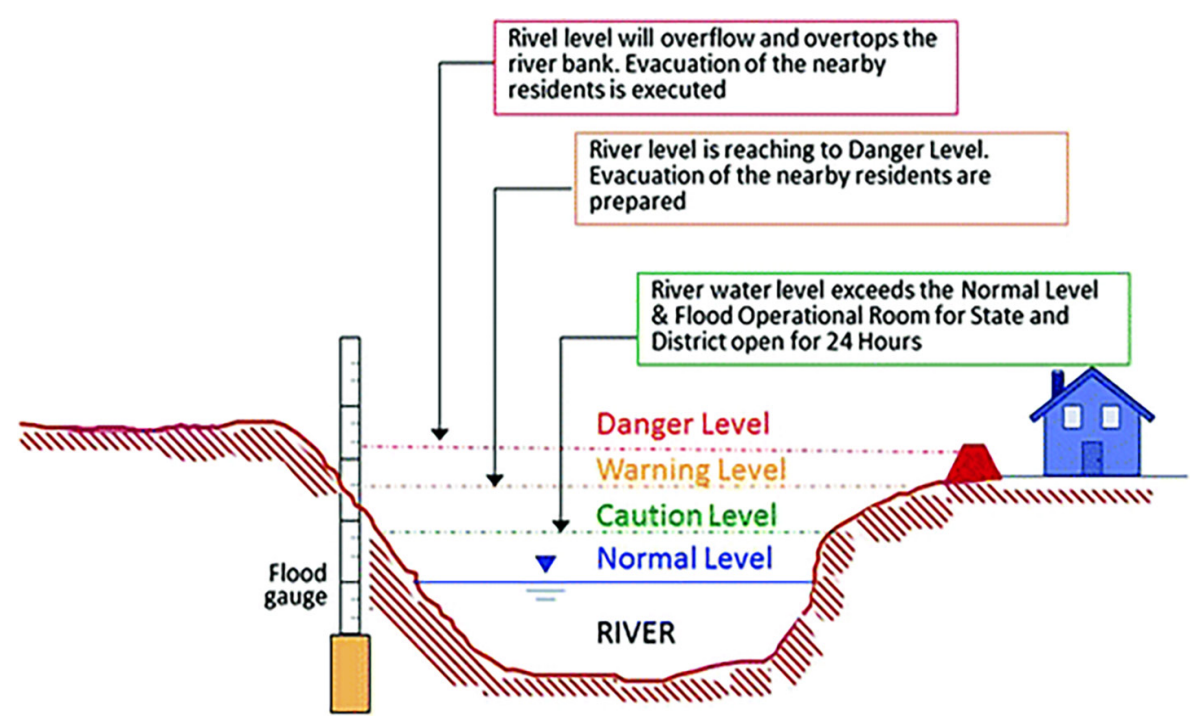

Figure 3: The Standard of Critical River Levels Termed by Department of Drainage and Irrigation Kelantan.

the areas of Bukit Sireh, Keroh, and Pulau Chondong for 13 hours. The floods hit several hospitals in Kelantan during the second wave on 22nd until 29th December 2014. The 2014 floods made them unable to provide optimal services and four hospitals were affected i.e. Hospital Kuala Krai, Hospital Tanah Merah, Hospital Pasir Mas, and Hospital Raja Perempuan Zainab II. Datuk Dr. Noor Hisham Abdullah, General Director of Health, confirmed that three hospitals namely Hospital Gua Musang, Hospital Kuala Krai, and Hospital Tanah Merah have been without electricity and operated only using generator power (9). Hospital failure to withstand disaster brings immense social implications such as the effect on public morale as a result of the death of the sick, elderly, and children in hospitals during disasters as well as a failure of emergency services when they are most needed (10). World Health Organization (11) reported that hospital's facility and services should remain accessible and function at maximum capacity and in the same infrastructure, during and immediately following the impact of a natural hazard.

The purpose of this study is to explore the present state of disaster preparedness in hospitals with special attention to the current floods, whether the hospitals in
Malaysia are prepared for major disasters. This will also assist the hospitals in determining which facilities and issues most urgently need interventions so that the hospitals will become more prepared when handling the disasters. This research studies several hospitals in Kelantan in terms of preparedness.

\section{METHODOLOGY}

A qualitative study was conducted through an in-depth face-to-face interview for a total of six samples comprising of four hospital personnel representing the Disaster Committee Members that were affected by the flood in December 2014. Creswell (12) suggested that the qualitative and quantitative method in mixed method approached must not use the same sample and a larger sample is required in the quantitative phase. Creswell (13) advised that five to 25 respondents are sufficient for a qualitative approach, meanwhile Morse (14) suggested that the maximum of six respondents are required for the same approach. Thus, this study had conducted an interview until the researcher achieved data saturation. The researcher had interviewed the Head of Disaster Management Committee of the hospital. 
The interviews were conducted in February and March 2017. A purposive sampling was used to select the samples among the hospital staff that are directly involved with the disaster committee members. Once the identified sample verbally consented for the interview, an in-depth face-to-face interview was performed in their respective hospitals. The samples were introduced to the interviewer and were briefed about the study purpose. The interview was conducted using guide questions to ensure similarity of interviewing method and flow of the discussions.

The data obtained was sorted according to various categories based on content analysis. Data analysis was carried out by studying and mapping according to the emerging themes.

\section{RESULTS}

The findings from the interviews were categorised into six main themes. The main themes identified are hospital disaster experience, preparations, factors affecting hospital disaster preparedness, disaster management policy, communication systems, and disaster preparedness model for hospitals. Please refer Table 1.

\section{Hospital Disaster Experience}

In terms of hospital disaster experience, the various responses was voiced out for each hospital. Most of the hospitals had experiences in flood disaster and 2014 flood was the only major disaster in their record. One of the hospitals was not focused to the flood because they are not facing flood every year compared to the other hospitals in this study.

"As I believe 2014's flood is the only major disasters on our record." (Respondent A)

"We have never experienced in any major disasters but we always handle the floods." (Respondent B)

"Since I worked in the year 2000 , the disaster that has been recorded correctly was 2014 flood." (Respondent C)

"The major disaster which we had faced was the 2014 flood." (Respondent D)

Table 1: Characteristics of hospital disaster preparedness

\begin{tabular}{|c|c|c|c|c|c|c|}
\hline \multirow{2}{*}{ Research variable- } & \multicolumn{6}{|c|}{ Respondents } \\
\hline & A & B & C & D & $\mathbf{E}$ & $\mathbf{F}$ \\
\hline Experience & Flood & Flood & Flood & Flood & Flood & Others \\
\hline Preparations & $\begin{array}{l}\text { Initial } \\
\text { preparation } \\
\text { Small-scale }\end{array}$ & $\begin{array}{l}\text { Initial } \\
\text { preparation } \\
\text { Small-scale }\end{array}$ & $\begin{array}{l}\text { Initial } \\
\text { preparation } \\
\text { Small-scale }\end{array}$ & $\begin{array}{l}\text { Initial } \\
\text { preparation } \\
\text { Small-scale }\end{array}$ & $\begin{array}{l}\text { Initial } \\
\text { preparation } \\
\text { Small-scale }\end{array}$ & $\begin{array}{l}\text { Initial } \\
\text { preparation } \\
\text { Small-scale }\end{array}$ \\
\hline $\begin{array}{l}\text { Factor } \\
\text { preparedness }\end{array}$ & Past experience & $\begin{array}{l}\text { Geographical } \\
\text { factors }\end{array}$ & Past experience & $\begin{array}{l}\text { Annual flood } \\
\text { disasters } \\
\text { Instruction from } \\
\text { superiors }\end{array}$ & $\begin{array}{l}\text { Instruction from } \\
\text { superiors }\end{array}$ & $\begin{array}{l}\text { Instruction from } \\
\text { superiors } \\
\text { Depends on the } \\
\text { disasters }\end{array}$ \\
\hline $\begin{array}{l}\text { Disaster } \\
\text { management } \\
\text { policy }\end{array}$ & Flood policy & Focus on flood & $\begin{array}{l}\text { All hazards } \\
\text { preparedness } \\
\text { protocol }\end{array}$ & Disaster policy & $\begin{array}{l}\text { Disaster action } \\
\text { plan }\end{array}$ & $\begin{array}{l}\text { Disaster action } \\
\text { plan } \\
\text { Protocol of flood } \\
\text { management }\end{array}$ \\
\hline $\begin{array}{l}\text { Communication } \\
\text { system }\end{array}$ & $\begin{array}{l}\text { Line } \\
\text { disconnected } \\
\text { Use GIRN }\end{array}$ & $\begin{array}{l}\text { System break } \\
\text { down } \\
\text { Only can use } \\
\text { GIRN }\end{array}$ & $\begin{array}{l}\text { Line } \\
\text { disconnected } \\
\text { Use GIRN }\end{array}$ & $\begin{array}{l}\text { Line } \\
\text { disconnected } \\
\text { Use GIRN }\end{array}$ & $\begin{array}{l}\text { Only available } \\
\text { for Celcom line } \\
\text { Use GIRN }\end{array}$ & $\begin{array}{l}\text { Only available } \\
\text { for Digi line } \\
\text { Use GIRN }\end{array}$ \\
\hline $\begin{array}{l}\text { Disaster } \\
\text { preparedness } \\
\text { model }\end{array}$ & Do not have & Do not have & Do not have & Do not have & Do not have & Do not have \\
\hline
\end{tabular}


"We do not have any issue in a major disaster. The major disaster that had affected us was the 2014 flood." (Respondent E)

"We have been handling various types of disasters well and controlled. The major disasters we had handle was Tsunami 2004 but we still in control." (Respondent F).

\section{Preparations}

In terms of preparations required during the disaster in the hospitals, all of the hospitals voiced out. Most of the hospitals have made early preparations to face any disaster that might occur at any time, but they cannot predict the scale of a disaster that might hit them.

"Yes, we make initial preparation for any possible disasters at any time. We have our own operating room to make it easier for the public to get information about the flood situation in the affected area." (Respondent A)

"There is no denying that hospitals take preliminary preparation to face the disasters especially when the monsoon season.” (Respondent B)

"Yes, we are always ready and depends on our leader who will give directions.” (Respondent C)

"We are prepared to face the disasters especially flood and our preparation depends on the situation.” (Respondent D)

"Yes, we are ready to handle any disasters at any time, but the hospital was more focused on floods as the most important risk here." (Respondent E)

"Yes, we are well prepared. In our hospital, we have the Emergency Response Team that will control our hospital before the firefighters come. When it comes to humaninduced disasters, Emergency
Department will be early prepared but when it comes to a disaster caused by a fire in our hospitals, we are still in making improvements for the preparations." (Respondent F)

\section{Factors that Affect Hospital Disaster Preparedness}

Regarding the factors that affected the hospital disaster preparedness, all sixhospitals gave the same factors which are the instructions from their superior.

"For me, I believe that instructions from the hospital directors who play an important role in the preparation of hospital disaster preparedness." (Respondent A)

"We need to be prepared because the hospital's geographical factors that are far from Kelantan River will make our hospital as a relief centre for flood-stricken hospitals." (Respondent B)

"One of the factors is, we will take action and plan for preparation after the occurrence of the event elsewhere." (Respondent C)

"Instructions from the superior, past experience, the flood that always struck, were the factors that affect the hospital disaster preparedness." (Respondent D)

"I believe that past experience is the main factor that affects the hospital disaster preparedness and the instructions from the top management.” (Respondent E)

"The factors of a hospital disaster preparedness differ as each hospital does not experience the same disasters and needs." (Respondent F)

\section{Disaster Management Policy}

In terms of disaster management policy, all the hospitals have the disaster policy and 
protocol but it depends on the frequent disaster that they face. Most of the hospitals are more focused because it occured annually.

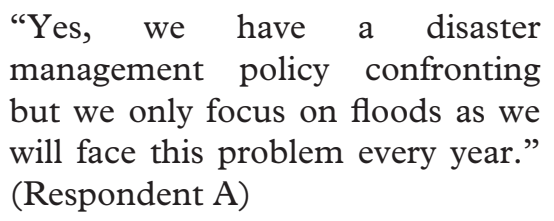

"Yes, we only have the policy for floods. For other disasters other than floods are controlled by the emergency departments." (Respondent B)

"We do not have the disaster management policy but we have a disaster management protocol. Previously, we had 'All Hazard Disaster Preparedness Protocol' which involved the occurrence of fire, flood, and others but not specific to specific disasters." (Respondent C)

"Yes, we are. We have a special flood policy to be used for the general disasters. This policy is constantly updated to make it a quality policy for hospital references." (Respondent D)

"We only have a disaster action plan rainwater and this plan is always improved especially from the flood experience of 2014. I believe each hospital must have its own disaster plan. Guidelines from Ministry of Health were used as our reference." (Respondent E)

"We only have the plan disasters action and protocol of disaster management." (Respondent F)

\section{Communication Systems}

Regarding the communication systems, all hospitals have total loss of communication system and unable to contact the authorities for external assistance. All of this six hospitals totally agree that the communication system had broken down and they cannot communicate with the authorities.

"The communication system at that time was disconnected. We can only use Government Integrated Radio Networking (GIRN) to get online to connect with authorities such as Angkatan Tentera Malaysia (ATM) to get food, drinks and electricity supplies." (Respondent A)

"We weren't able to contact our staff who work on that day and we cannot identify their location because the communication has been disconnected. Our Emergency Department has used the walkietalkie tool as a communication tool during the 2014 flood for areas with no telephone connections." (Respondent B)

"The communication system was disconnected. We just used GIRN to contact with the authorities for assistance." (Respondent C)

"The communication system was disconnected. We can only use GIRN to contact the ATM." (Respondent D)

"The communication system was disconnected but only Celcom lines can be used as there were Celcom substations on the hill in this area. Only phones with Celcom lines and GIRN can be used at that time. GIRN can only be used outdoors. GIRN was used to connect with the police, ATM, Jabatan Kebajikan Kelantan, and others.” (Respondent E)

"If the communication system were disconnected, only the phones with Digi lines can be used here. We have no experience of having lost communication systems so far, but the GIRN tools will be used to contact the authorities."(Respondent F) 


\section{Disaster Preparedness Model}

In terms of Disaster Preparedness Model, all these six hospitals do not have disaster preparedness model that needs to be same coordinated among the hospitals when a disaster happens. This is because they can follow the disaster preparedness model to control the situation during disaster occured. Besides, they will know their roles when disaster hit the hospitals.

\begin{abstract}
"We just have our own disasters policy. We do not have any model of hospital disaster preparedness." (Respondent A)
\end{abstract}

"We do not have a disaster preparedness model but we do have our action plan for floods that will always be updated." (Respondent B)

"So far, we do not have the model." (Respondent C)

"We just follow our policy for disaster and we do not have the disaster preparedness model.” (Respondent D)

"We do not have the disaster preparedness model." (Respondent E)

"We just have the action plan for disasters and we do not have the disaster preparedness model." (Respondent F)

\section{DISCUSSION}

Based on the interviews conducted with the hospital disaster committee affected by the 2014 extraordinary flood in Kelantan, the results showed the actual situation in several hospitals that were affected by the flood. Kelantan was chosen because it is considered as the latest worst flood disaster in Malaysia. Hospitals play an important role in providing protection and proper treatment for the disaster victims, including the critical and non-critical cases if any disaster occurred at any time. Among the organizations and involving institutes, hospitals play the most important role as an essential facility for providing services to those needed.

This study showed that the 2014 flood hit several hospitals in Kelantan had caused these hospitals unable to provide the optimal services and the level of preparedness to the disaster is still in low condition. This is because no one can estimate the condition of the disaster in small or large scale. These hospitals were more focused on floods as the more important risk in Kelantan was the flood and do not have any big problem in any various type of disasters such as fire issues, mass casualty accidents, and epidemics. The hospital provides in terms of equipment, staff and action plans when the flood has occurred.

From the aspect of hospitals disaster preparedness, before the 2014 flood, the hospitals were well prepared to handle the flood like the current year as they didn't expect it came out as big floods. The main cause of the 2014 flood due to the overwhelming amount of rainwater. So, hospital response depends on the phase of floods at that time. The first phase, the usual flood that involves the stuck route and second phase, when the floods are huge, there are many problems that have been identified such as the risk of sinking based on the flood experience 2014, lost power supply and out of clean water supply. Most of these hospitals do not have the specific disaster committee to handle if any disasters occurred.

Based on the factors that affect hospital preparedness in the face of disasters, most of these hospitals just wait for directions from the superior to be well prepared for disasters. In addition, one of the factors that affect the level of hospital readiness is through the past experience such as 2014 floods. This past experience has affected the hospital to further improve the level of preparation and more alert to any disaster. 
For the disaster management policy, every hospital has their own disaster management policy and action plan for their own references. Since the disaster risk is not the same between different hospitals, each disaster action plan should be tailored to the needs of each hospital. Most of the policy and action plan in the hospitals in Kelantan are more focused to the flood because it is a major disaster that annually occurred in Kelantan.

Next, the communication systems when disaster strikes is one of the variables in this study. The communication system was totally disconnected when the floods hit several areas in Kelantan. These hospitals have to use GIRN to get assistance and information from authorities such as police, ATM, and Jabatan Kebajikan Negeri. Besides, the GIRN can only be used outside of the building to get signal.

For the disaster preparedness model section, all of this hospital in this study didn't have any model disaster that is same input as a guideline when any disasters occurred. They do not have a disaster preparedness model but they have their action plan for floods that will always be updated. This action plan should have four phases that must have in each hospital plan as a reference to face any disaster. The four phase is prevention, preparedness, response, and recovery. Figure 4 shows a Disaster Risk Management Model in a cyclic and iterative process (15). These are the pre- and post-disaster activities to all the phase of the disaster risk management cycle.

This disaster risk management model highlights the importance of addressing and underlying factors that lead to the disaster. It is important to discovering a clearer understanding and response to the disaster management. Therefore, this cycle is very important to be apply in every hospital action plan in facing the catastrophes.

\section{RECOMMENDATIONS FOR FUTURE WORK}

In fact, the hospital disaster preparedness is unsatisfactory in terms of assessing the effectiveness of its implementation to obtain the perception of the victim itself. This study show that in Malaysia, a study concerning the hospital disaster preparedness at levels during and postdisaster was poorly implemented. With reference to the data from the face-toface interview on the hospital disaster preparedness when the disasters occurred, some recommendation has been proposed for improvement.

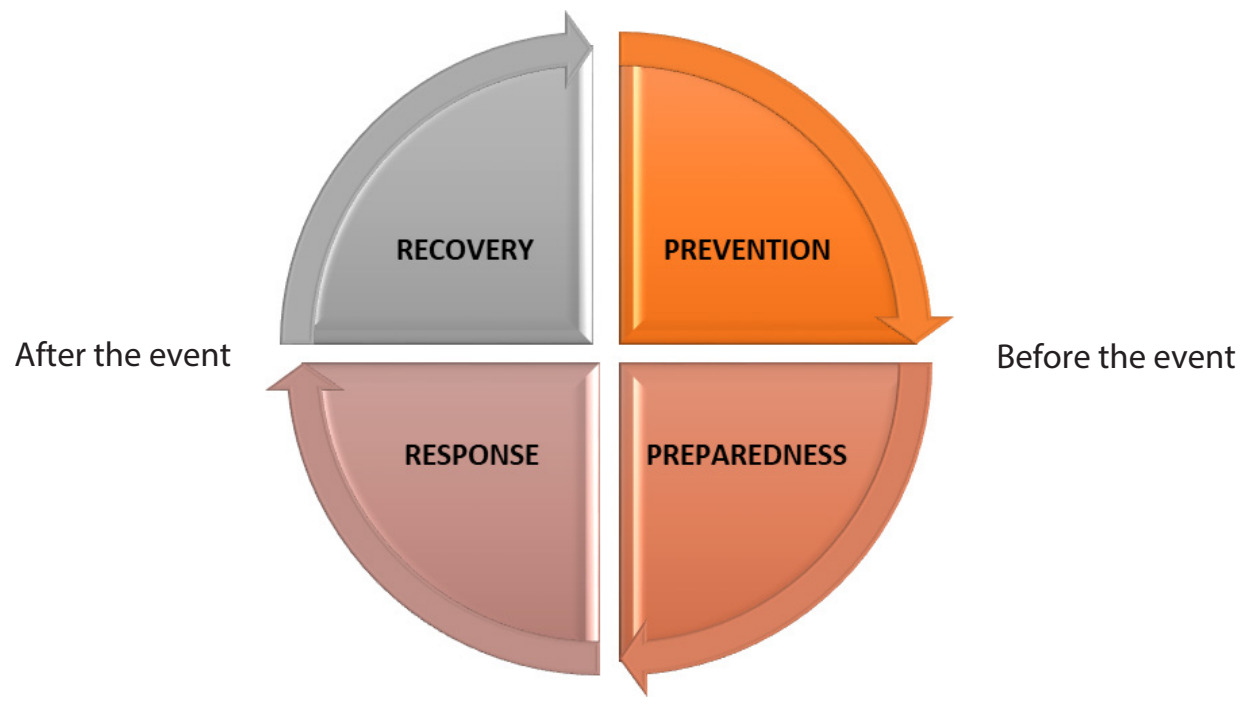

Figure 4: Disaster risk management model. 


\section{Prevention}

One of the recommendations that we propose is to relocate facilities to an identified and upgraded safe area in order to comply with the flood risk management requirements. This is because all the equipment can be saved without any damage and loss during the flood. A safe place for this facility should be in a high place and not able to be flooded.

Next recommendation for prevention phase is to install an integrated flood warning system. This system can signal the hospital and the disaster management officer can declare a disaster, so everyone can prepare and get ready to deal with the disaster.

\section{Preparedness}

For preparedness phase, the recommendation that we propose is to provide staff with the latest database. The problem that occurred during the 2014 flood was, hospitals could not identify their staff that supposed to work had become flood victims. The hospital also cannot track their staff location during the 2014 flood. So, it is a need to provide the latest staff database.

Besides, we need to ensure the availability of stand-alone electrical generator at appropriate location enough to meet the needs with the adequate power capacities. Due to 2014 flood, hospitals having the problem with the loss power supply which is important for them to survive and handling patients. Some hospitals have their own stand-alone electrical generator but not all the hospital have the stand-alone electrical.

\section{Response}

Next recommendation in the response phase is the authorities should provide rehabilitation centre equipped with safe tube wells and generators in preparation for flood disaster. A hospital should have an appropriate rehabilitation centre that has all the amenities to provide enough water and power supply. According to the 2014 flood experience, the supply of clean water is not enough to accommodate all victims in the operation centre.

The hospital is also needing to provide transportation for hospital and clinic staff during the flood. This is because, the hospitals can collect their staff to work to and overcome the problem of staff shortage during the disaster happen.

\section{Recovery}

Next recommendation is hospitals should require attending a mandatory training session on how to handle the disaster in hospitals. As a part of the training competency, each training session was concluded with the completion of a written examination and drills practically. This is to ensure that all the staff are ready and prepare to face the disaster in the future.

The hospitals also need to recover documents and patient records immediately. Therefore, hospital need to make sure that there is a backup system for health record. If the record of the patient is flooded or lost, the treatment services will be difficult to get the patient database.

\section{CONCLUSION}

Malaysia is free from natural disasters such as volcanic eruptions, earthquakes, hurricanes, tsunamis, typhoon, and tornadoes because Malaysia is located in a geologically stable region just outside the "Pacific Ring of Fire". It also lies too far south of major typhoon paths (16). The most severe hazards experienced in Malaysia is flooded. Floods are the most devastating natural disasters that occurred in Malaysia. Like the other hazards, the flood can cause fatalities from drowning and damages to properties such as the house, building, cars, plantations, and others. Malaysia's National Security Council (NSC) said that the 2014 
flood in Kelantan was the worst recorded in the history of the state. The primary factor of the flood in Malaysia is the incidence of heavy monsoon or continuously rainfall and as a result, a large concentration of overflow which worsened due to rapid development in the river catchment and deteriorated river capacity.

In addition, successful execution of a disaster plan relies on the frequent practice of disaster drills in the hospital and community and must involve multiple agencies for assistance. Datuk Mohamed Thajudeen Abdul Wahab explained that disaster management is handled at three levels which are the district, state, and federal (6). Therefore, these multiple agencies need to do a frequent practice of disaster drills together with the hospitals to have the same coordinate with the hospitals to face the disasters.

Disaster preparedness is an obviously important thing as the first step in the face of any disaster that might be happening at any time. Thus, disaster preparedness is not an easy undertaking in any hospital setting. It is an essential to have a strong framework which to operate, specifically an up-to-date disaster action plan that have details internal and external for disaster response system. It is a need for all the hospital to have an action plan which include the four phase of disaster risk management. This action plan will have the phase for post- and predisaster. A smart disaster plan will facilitate the movement of the hospitals in the event of disasters as all employees are aware of the steps to be taken during the disasters and it is a model for hospital disaster preparedness.

\section{ACKNOWLEDGEMENTS}

The authors gratefully acknowledge the Fundamental Research Grant Scheme (FRGS) for financial support. The authors are also thankful for the cooperation of hospitals in Kelantan regions and Universiti Sains Malaysia in conducting this study.
With regard to the ethical standards, some information related to the under examined hospital including its name and detailed findings are kept confidential by the researchers, as requested.

\section{REFERENCES}

1. Gebbie KM, Qureshi K. Emergency and disaster preparedness: core competencies for nurses. Am J Nurs. 2002;102(1): 46-51. https://doi.org/10.1097/00000446-2002 01000-00023

2. United Nations International Strategy for Disaster Reduction (UNISDR). UNISDR terminology on disaster risk reduction. Geneva: UNISDR; 2009.

3. Ben-Ezra M, Palgi Y, Aviel O, Dubiner Y, Baruch E, Soffer Y, Shrira A. Face it: collecting mental health and disasterrelated data using Facebook vs. personal interview: the case of the 2011 Fukushima nuclear disaster. Psychiatry Res. 2013;208(1): 91-3. https://doi.org/10.1016/j. psychres.2012.11.006

4. Khor M. Lessons from great floods. The Star Online. 19 January 2015 [cited 13 November 2017]. Available from: https:// www.thestar.com.my/opinion/columnists/ global-trends/2015/01/19/1essons-from-thegreat-floods/

5. eBanjir Negeri Kelantan. Laporan catatan aras air tertinggi mengikut tempat. 2014 [cited 21 December 2017]. Available from: http://ebanjir.kelantan.gov.my/p_parpt0 1 . php

6. Azlee A. Worst floods in Kelantan, confirms NSC. The Malay Mail. 5 January 2015 [cited May 2015]. Available from: https://www.malaymail.com/news/ malaysia/2015/01/05/worst-floods-inkelantan-confirms-nsc/813959 
7. The Star Online. Situation continues to worsen in badly-hit Kelantan and Terengganu. 25 December 2014 [cited January 2017]. Available from: https://www. thestar.com.my/news/nation/2014/12/25/ number-of-flood-evacuees-soars-situationcontinues-to-worsen-in-badlyhit-kelantanand-terengganu/

8. Bernama. Hospitals and clinics destroyed in floods estimated at RM 281 million. Astro Awani. 10 January 2015 [cited May 2015]. Available from: http://english. astroawani.com/flood-news/hospitals-andclinics-destroyed-floods-estimated-rm281mil-28754

9. Abdullah NH. Kenyataan akhbar - ketua pengarah kesihatan kementerian kesihatan Malaysia: tindakan kementerian menangani banjir; 2014 [cited June 2016]. Available from: file:///C:/Users/DELL/Downloads/ KENYA T A A N \% 20 A K H B A R \% 20 TINDAKAN $\% 20$ KEMENTERIAN $\% 20$ MENANGANI $\% 20$ BANJIR $\% 2028 \% 20$ DISEMBER\%202014.pdf

10. Md Yusoff AS. Hospital di Kelantan kritikal. Utusan Online. 26 December 2014 [cited 20 May 2015]. Available from: http://www. utusan.com.my/berita/nahas-bencana/ hospital-8232-di-kelantan-kritikal-1.40969
11. World Health Organization. Safe hospitals initiatives: comprehensive safe hospital framework. Geneva: WHO; 2015 [cited July 2017]. Available from: http://www.who. int/hac/techguidance/comprehensive_safe_ hospital_framework.pdf?ua=1

12. Creswell JW. Research design: qualitative, quantitative and mixed methods approaches. USA: Sage Publications; 2014.

13. Creswell JW. Qualitative inquiry \& research design: choosing among five approaches. 2nd ed. USA: Sage Publications; 2007.

14. Morse JM. Designing funded qualitative research. In: Denizin NK, Lincoln YS, editors. Handbook of qualitative research. 2nd ed. Thousand Oaks, CA: Sage Publications; 1994.

15. Mercy Malaysia. Total disaster risk management. 2005 [cited June 2017]. Available from: https://www.mercy.org.my/ our-approach/

16. Chan N. Impacts of disasters and disaster risk management in Malaysia: the case of floods. In: Aldrich DP, Oum S, Sawada Y, editors. Resilience and recovery in Asian disasters. Japan: Springer; 2015. p. 239-65. 